\title{
ANALISIS DENGAN MENGGUNAKAN METODE ALTMAN Z- SCORE, SPRINGATE (S-SCORE) DAN ZMIJEWSKI SEBAGAI SIGNALING KEBANGKRUTAN PADA PERUSAHAAN MANUFAKTUR SEKTOR OTOMOTIF YANG TERDAFTAR DI BEI PERIODE 2015-2017
}

\author{
Agnes Mega Widiastuti \\ Program Studi Magister Manajemen Universitas Tarumanagara \\ agnesmegaw@gmail.com
}

\begin{abstract}
The purpose of this study was to determine the predictions of bankruptcy in the Automotive Sector Manufacturing Companies listed in Indonesia Stock Exchange for the period 2015-2017 based on the results of the Altman Z-score, Springate (S-score) and Zmijewski method analysis. This study uses secondary data, it was the annual financial report of the Automotive Sector Manufacturing Company for the period 2015-2017 using the technique of documentation and analyzed by the Altman Z-score method, Springate (Sscore), and Zmijewski. The final results of this study indicate that there is a difference in the percentage of bankruptcy rates of each company from each method used. The results of the prediction of the Altman Z-score bankruptcy method, it was the bankrupt category of $25.00 \%$, the non-bankrupt category of $8.33 \%$ and the grey area category of $66.67 \%$. The prediction results of Springate (S-score) bankruptcy method, it was the bankrupt category of $66.67 \%$, and the non-bankrupt category of $33.33 \%$. The prediction results of Zmijewski bankruptcy method, it was the bankrupt category of $8.33 \%$, and the non-bankrupt category by $91.67 \%$.
\end{abstract}

Abstrak :Tujuan penelitian ini untuk mengetahui prediksi kebangkrutan pada Perusahaan Manufaktur Sektor Otomotif yang terdaftar di Bursa Efek Indonesia Periode 2015-2017 berdasarkan hasil analisis metode Altman Z-score, Springate (S-score), dan Zmijewski. Penelitian ini menggunakan data sekunder yaitu laporan keuangan tahunan pada Perusahaan Manufaktur Sektor Otomotif periode 2015-2017 dengan menggunakan teknik pencatatan dokumen dan dianalisis dengan metode Altman Z-score, Springate (S-score), dan Zmijewski. Hasil akhir penelitian ini menunjukan adanya perbedaan persentase tingkat kebangkrutan tiap perusahaan dari tiap-tiap metode yang digunakan. Hasil prediksi kebangkrutan metode Altman Z-score, yakni kategori bangkrut sebesar 25,00\%, kategori tidak bangkrut sebesar $8,33 \%$ dan kategori grey area sebesar 66,67\%. Hasil prediksi kebangkrutan metode Springate (S-score), yakni kategori bangkrut sebesar $66,67 \%$, dan kategori tidak bangkrut sebesar 33,33\%. Hasil prediksi kebangkrutan metode Zmijewski, yakni kategori bangkrut sebesar $8,33 \%$, dan kategori tidak bangkrut sebesar 91,67\%.

Keywords : Predictions of Bankruptcy, Altman Z-Score, Springate (S-Score), and Zmijewski Method

\section{PENDAHULUAN}

Saat ini industri otomotif dipandang sebagai salah satu sektor industri non-migas yang memberi kontribusi cukup besar terhadap pertumbuhan ekonomi nasional. Data dari ASEAN Automotive Federation yang dipublikasikan dalam studi automotive-cluster.org menunjukkan Indonesia saat ini merupakan salah satu pemain penting di industri otomotif Asia Tenggara dan merupakan negara produsen otomotif terbesar kedua. Tidak hanya memenuhi kebutuhan konsumsi dalam negeri, saat ini Indonesia juga terus dikembangkan untuk menjadi basis produksi global. Mengutip dari artikel Kompas.com, pengamat ekonomi Faisal Basri mengatakan dijadikannya Indonesia sebagai basis produksi global akan memberi efek positif 
bagi perekonomian di Indonesia. Akhir tahun 2016 lalu industri otomotif tercatat menyumbang 10,47\% dari total PDB nasional.

Tidak berlebihan jika industri otomotif saat ini termasuk ke dalam sebelas sektor industri non-migas yang dijadikan prioritas untuk dikembangkan pemerintah dan sebagai barometer laju ekonomi nasional. Wakil Presiden Jusuf Kalla, dikutip dalam Kompas.com, mengatakan bahwa jika industri otomotif berkembang maka sektor industri pendukungnya akan ikut berkembang. Maka jika industri otomotif mengalami penurunan akan terjadi penurunan pula pada sektor industri pendukungnya. Setiap perusahaan didirikan dengan harapan akan menghasilkan profit sehingga mampu untuk bertahan dan berkembang dalam jangka waktu panjang. Dalam praktiknya, asumsi seperti di atas tidak selalu menjadi kenyataan. Seringkali perusahaan yang telah beroperasi dalam jangka waktu tertentu terpaksa bubar karena mengalami financial distress yang berujung pada kebangkrutan.

Publikasi laporan keuangan tahunan serta rating industri maupun hasil pengolahan rasio oleh pihak BEI, dapat menunjukkan kondisi keuangan suatu perusahaan go-public. Informasi BEI tersebut diharapkan akan mampu memberikan sinyal bagi investor maupun calon investor mengenai kinerja perusahaan. Analisis terhadap laporan keuangan memerlukan suatu ukuran dan cara, di mana dapat memberikan pandangan yang lebih baik mengenai kondisi keuangan suatu perusahaan yang dapat dipergunakan sebagai bahan pertimbangan untuk proses pengambilan keputusan manajemen. Adapun kelemahan dari analisis laporan keuangan adalah hanya menekankan pada aspek keuangan saja, maka dari itu diperlukan suatu alat analisis untuk menggabungkan berbagai aspek keuangan tersebut, alat tersebut yakni analisis prediksi kebangkrutan.

Analisis prediksi kebangkrutan yang sering digunakan yakni, analisis metode Altman ZScore, Springate (S-score) dan Zmijewski. Analisis tersebut dikenal karena keakuratannya dalam menentukan prediksi kebangkrutan suatu perusahaan, tidak hanya diperuntukkan bagi perusahaan yang tidak sehat saja melainkan untuk perusahaan-perusahaan yang dianggap sehat. Analisis ini dilakukan sebagai tindak preventif bagi perusahaan yang sehat dan merupakan tindakan kuratif bagi perusahaan yang tidak sehat. Dengan tujuan untuk menghindari atau meminimalisir resiko kebangkrutan perusahaan.

\section{TINJAUAN PUSTAKA}

\section{Laporan Keuangan}

Menurut Pandey (sebagaimana dikutip dari Haruna, Danjuma, \& Worsen, 2016) Financial statements are the means of communicating to shareholders and other interested parties' information on the financial resources, obligations and performances of the reporting entity or enterprise. Such information usually assists shareholders and other interested parties in assessing the financial liquidity, profitability and viability of the company. Tujuan laporan keuangan berdasarkan SAK yang dikeluarkan oleh Ikatan Akuntan Indonesia adalah untuk menyediakan segala informasi penting yang menyangkut posisi keuangan, kinerja, dan perubahan posisi keuangan pada suatu perusahaan yang dapat bermanfaat dalam pengambilan keputusan. Analisis laporan keuangan adalah proses untuk mempelajari data keuangan agar dapat dipahami dengan mudah untuk mengetahui kondisi keuangan, dengan cara mempelajari hubungan setiap data keuangan serta kecenderungan yang terdapat dalam laporan keuangan. Dalam melakukan analisisnya tidak akan lepas dari peranan rasio-rasio laporan keuangan.

\section{Teori Signaling}

Menurut Sari dan Zuhrotun (2006), Teori signal menjelaskan mengapa perusahaan mempunyai dorongan untuk memberikan informasi laporan keuangan kepada pihak eksternal, agar perusahaan memiliki hubungan baik dan kredibel di mata investor. Hubungan baik akan 
terus berlanjut jika investor puas dengan kinerja perusahaan, dan penerima sinyal juga menafsirkan sinyal perusahaan sebagai sinyal yang positif. Laporan tentang kinerja perusahaan yang baik akan meningkatkan nilai perusahaan.

\section{Pengertian Kebangkrutan}

Menurut Br Ferdinand D. Saragih (sebagaimana dikutip dari Lili \& Trisnadi, 2013) Kebangkrutan adalah suatu kondisi disaat perusahaan mengalami ketidakcukupan dana untuk menjalankan usahanya. Semakin awal tanda-tanda kebangkrutan tersebut ditemukan, semakin baik bagi pihak manajemen, karena dapat melakukan perbaikan sejak awal. Kebangkrutan tidak akan terjadi jika tanpa adanya penyebab kebangkrutan itu sendiri. Penyebab kebangkrutan dapat berasal dari faktor internal dan eksternal perusahaan.

\section{Analisis Kebangkrutan}

Untuk meminimalisir resiko kebangkrutan, diperlukan suatu alat atau metode prediksi yang dapat digunakan untuk memprediksi ada atau tidaknya potensi kebangkrutan perusahaan dan menilai kapan perusahaan akan bangkrut dengan menggabungkan sekelompok rasio keuangan. Salah satu faktor yang menopang perusahaan agar tetap beroperasi adalah faktor finansial atau kondisi keuangan perusahaan, sehingga banyak peneliti yang telah mengembangkan metode prediksi kebangkrutan.

\section{Metode Altman Z-Score}

Pada tahun 1968 Edward I. Altman menemukan suatu formula atau metode untuk memprediksi potensi kesulitan keuangan dimasa yang akan datang yang disebut sebagai metode Z Score. Menurut Sartono (sebagaimana dikutip dari Anggi Meiliawati, 2016 ) Z Score adalah skor yang ditentukan dari hitungan standart dikalikan rasio - rasio keuangan yang akan menunjukan tingkat kemungkinan kebangkrutan perusahaan. Altman Z-score menggunakan teknik statistik (Multiple Discriminant Analysis) untuk menghasilkan alat prediksi yang merupakan fungsi linier dari beberapa variable penjelas. Output dari teknik MDA adalah persamaan linear yang bisa membedakan antara dua keadaan variabel dependen. Kelima rasio yang digunakan altman dimasukkan ke dalam analisis MDA dan menghasilkan metode sebagai berikut :

Keterangan :

$$
Z=1.2 X_{1}+1.4 X_{2}+3.3 X_{3}+0.6 X_{4}+0.999 X_{5}
$$

$$
\begin{aligned}
& \begin{array}{l}
Z \\
=\text { Bankrupty Index }
\end{array} X_{1}=\frac{\text { Working Capital }}{\text { Total Assets }} \\
& X_{3}=\frac{\text { EBIT }}{\text { Total Assets }} \quad X_{4}=\frac{\text { Market Value of Equity }}{\text { BookValue of Total Debt }} \quad X_{5}=\frac{\text { Total Assets }_{\text {Sales }}^{\text {Total Assets }}}{\text { Tot }} \\
& X_{2} \\
& =\frac{\text { Retained Earnings }}{\text { Total Assets }}
\end{aligned}
$$

Dengan kriteria penilaian sebagai berikut :

a. Jika nilai $Z<1,81$ maka termasuk perusahaan yang bangkrut.

b. Jika nilai $1,81<Z>2,99$ maka termasuk grey area ( tidak dapat ditentukan apakah perusahaan sehat ataupun mengalami kebangkrutan ).

c. Jika nilai $Z>2,99$ maka termasuk perusahaan yang tidak bangkrut. 


\section{Metode Springate (S-Score)}

Gordon L.V Springate (1978) akhirnya menggunakan Multi Discriminant Analysis (MDA) untuk memilih 4 rasio dari 19 rasio yang digunakan untuk memprediksi adanya potensi kebangkrutan perusahaan. Keempat rasio tersebut adalah working capital to total asset, earning before interest and tax to total asset, earning before tax to current liabilities, and sales to total asset, yang kemudian juga dikombinasikan dalam suatu formula yang disebut dengan metode springate. Menurut Kasingilam dan Ramasundaram (sebagaimana dikutip dari Lukman \& N. Ahmar, 2015 ) menyatakan bahwa metode springate dapat digunakan dalam memprediksi kebangkrutan perusahaan dengan melaporkan tingkat keakuratan yang lebih tinggi dari pada model lainnya. Adapun formula yang berhasil ditemukan oleh Springate adalah :

Keterangan :

$$
S=1.03 X_{1}+3.07 X_{2}+0.66 X_{3}+0.4 X_{4}
$$

$S$

= Bankrupty Index

$$
\begin{aligned}
& X_{1} \text { Current Assets }- \text { Current Liabilities } \\
& \text { Total Assets } \\
& X_{2}=\frac{\text { Earning Before Interest and Tax }}{\text { Total Assets }}
\end{aligned}
$$

$\boldsymbol{X}_{3}$ $=\frac{\text { Earning Before Tax }}{\text { Current Liabilities }}$

$$
X_{4}=\frac{\text { Sales }}{\text { Total Assets }}
$$

Dengan kriteria penilaian sebagai berikut :

a. Jika nilai S-score yang didapat > 0,862 maka perusahaan masuk ke dalam kategori sehat

b. Jika nilai S-score yang didapat $<0,862$ maka perusahaan masuk ke dalam kategori bangkrut

\section{Metode Zmijewski}

Metode Zmijewski menggunakan rasio keuangan return on asset (ROA), leverage, dan likuiditas untuk mendapatkan pola yang lebih tepat. Rasio keuangan ini dipilih bukan berdasarkan teori tetapi berasal dari pengalaman dan penelitian sebelumnya. Perluasan studi dalam prediksi kebangkrutan dilakukan oleh Zmijewski pada tahun 1983 yang menambah validitas rasio keuangan sebagai alat deteksi kegagalan keuangan perusahaan. Metode yang berhasil dikembangkan yaitu:

Keterangan :

$$
X=-4,3-4,5 X_{1}+5,7 X_{2}-0,004 X_{3}
$$

$$
\begin{array}{ll}
X=\text { Bankrupty Index } & X_{1}=\text { Return On Asset }(\text { ROA) } \\
X_{2} & X_{3} \\
=\text { Debt Ratio (Leverage) } & =\text { Current Ratio (Likuiditas) }
\end{array}
$$

Zmijewski menyatakan bahwa perusahaan dianggap bangkrut jika probabilitasnya $\mathrm{x}>0$. Hal ini berarti, perusahaan yang nilai $\mathrm{x}<0$ diprediksi tidak akan mengalami kebangkrutan. ( Randi dan Nurmala, 2017, p. 152 ).

\section{METODE PENELITIAN}

Pada penelitian ini dilakukan analisis deskriptif komparatif. Menurut Sugiyono (2008) penelitian deskriptif adalah penelitian yang dilakukan untuk mengetahui nilai variabel mandiri, baik satu variabel atau lebih (indepeden) tanpa membuat perbandingan, atau menghubungkan antara variabel satu dengan variabel yang lain. Menurut Sugiyono (2008) penelitian komparatif adalah penelitian yang variabelnya masih sama dengan penelitian mandiri tetapi untuk sampel yang lebih dari satu atau dalam waktu yang berbeda. Metode 
komparatif ini dilakukan untuk mengetahui dan mendeskripsikan signaling (prediksi) kebangkrutan Perusahaan Manufaktur Sektor Otomotif yang Terdaftar di BEI Periode 20152017 berdasarkan hasil analisis metode Altman (Z-Score), metode Springate (S-Score) dan metode Zmijewski.

Peneliti menggunakan model purposive sampling dalam pemilihan sampel. Menurut Indriantoro (sebagaimana dikutip dari Niken, 2017) model purposive sampling adalah model pemilihan sample secara tidak acak yang informasinya diperoleh dengan menggunakan pertimbangan dan kriteria tertentu dengan tujuan penelitian. Perusahaan yang akan menjadi sampel penelitian ini memiliki kriteria sebagai berikut :

- $\quad$ Perusahaan Manufaktur Sektor Otomotif yang Terdaftar di BEI

- Memiliki laporan keuangan tahunan yang lengkap periode tahun 2015-2017

\section{Teknik Analisis Data}

Langkah-langkah yang dilakukan pada analisa ini, meliputi :

- $\quad$ Pemilihan sampel sesuai dengan kriteria yang sudah ditentukan

- Melakukan perhitungan pada rasio-rasio perusahaan yang sesuai dengan variabelvariabel dalam metode Altman (Z-Score), Springate (S-Score) dan Zmijewski

- Membandingkan hasil olahan data sesuai dengan penerapan metode Altman (Z-Score), Springate (S-Score) dan Zmijewski pada perusahaan Manufaktur Sektor Otomotif yang terdaftar di BEI yang menjadi sampel penelitian

- Membuat kesimpulan dan saran berdasarkan hasil analisa tersebut.

\section{HASIL PENELITIAN DAN PEMBAHASAN}

Penelitian ini menggunakan tiga metode yang diterapkan pada 8 perusahaan otomotif yang tercatat di BEI tahun 2015-2017. Ketiga metode ini yakni, metode Altman Z- Score, metode Springate (S-score) dan metode Zmijewski.

\section{Hasil Analisis Kebangkrutan Metode Altman Z- Score}

Berdasarkan perhitungan pada tahun 2015 terdapat 5 perusahaan diprediksikan dalam kategori grey area (ASII dengan skor 2,2555, BOLT dengan skor 2,3255, GDYR dengan skor 1,8655, IMAS dengan skor 2,5338, dan SMSM dengan skor 2,5710) dan 3 perusahaan otomotif lainnya diprediksikan mengalami kebangkrutan (AUTO dengan skor 1,4444, BRAM dengan skor 1,2863, dan PRAS dengan skor 0,9968).

Pada tahun 2016 terdapat 1 perusahaan diprediksikan dalam kategori tidak bangkrut (SMSM dengan skor 2,9910 lebih baik dari skor tahun sebelumnya), 6 perusahaan otomotif diprediksikan dalam kategori grey area (ASII dengan skor 2,2126, AUTO dengan skor 1,8529, BOLT dengan skor 1,8600, GDYR dengan skor 1,8340, BRAM dengan skor 1,8986, dan PRAS dengan skor 2,8937 dan 1 perusahaan dalam kategori bangkrut (IMAS dengan skor 1,7808).

Pada tahun 2017 terdapat 1 perusahaan diprediksikan dalam kategori tidak bangkrut (SMSM dengan skor 3,0283, setiap tahunnya selalu menunjukan presentase yang cukup baik, nampaknya management dapat meningkatkan kinerja perusahaan sesuai dengan apa yang direncanakan), 5 perusahaan otomotif diprediksikan alam kategori grey area (ASII dengan skor 1,9205, AUTO dengan skor 1,9403, BRAM dengan skor 2,0301, IMAS dengan skor 2,0894 dan PRAS dengan skor 2,4544. ) dan 2 perusahaan dalam kategori bangkrut (BOLT dengan skor 1,7545 dan GDYR dengan skor 1,5300).

\section{Hasil Analisis Kebangkrutan Metode Springate (S- score)}

Berdasarkan perhitungan pada tahun 2015 terdapat 2 perusahaan diprediksikan dalam kategori tidak bangkut (BOLT dengan skor 2,1982 dan SMSM dengan skor 2,2025) dan 6 perusahaan otomotif lainnya diprediksikan mengalami kebangkrutan (ASII dengan skor 
0,7618, AUTO dengan skor 0,2839, GDYR dengan skor 0,4538, BRAM dengan skor 0,8041, IMAS dengan skor 0,1721 dan PRAS dengan skor 0,1678).

Pada tahun 2016 terdapat 3 perusahaan diprediksikan dalam kategori tidak bangkut (BOLT dengan skor 1,9215, BRAM dengan skor 1,0877 dan SMSM dengan skor 2,5321) dan 5 perusahaan otomotif lainnya diprediksikan mengalami kebangkrutan (ASII dengan skor 0,7262, AUTO dengan skor 0,4057, GDYR dengan skor 0,5553, IMAS dengan skor 0,1973 dan PRAS dengan skor 0,1134).

Pada tahun 2017 terdapat terdapat 3 perusahaan diprediksikan dalam kategori tidak bangkut (BOLT dengan skor 1,5807, BRAM dengan skor 1,2898 dan SMSM dengan skor 2,9068) dan 5 perusahaan otomotif lainnya diprediksikan mengalami kebangkrutan (ASII dengan skor 0,7935, AUTO dengan skor 0,4815, GDYR dengan skor 0,4103, IMAS dengan skor 0,1110 dan PRAS dengan skor 0,1056). Hal ini sama dengan tahun 2016 hanya saja setiap skor perusahaan berbeda-beda ada yang mengalami kenaikan dan ada yang mengalami penurunan

\section{Hasil Analisis Kebangkrutan Metode Zmijewski}

Berdasarkan perhitungan pada tahun 2015 terdapat 7 perusahaan diprediksikan dalam kategori tidak bangkut (ASII dengan skor -1,8304, AUTO dengan skor -2,7387, BOLT dengan skor -3,8151, GDYR dengan skor -1,2580, BRAM dengan skor -2,3741, PRAS dengan skor -1,4311, dan SMSM dengan skor -3,2413) dan hanya 1 perusahaan otomotif (IMAS dengan skor 0,0861).

Pada tahun 2016 terdapat 7 perusahaan diprediksikan dalam kategori tidak bangkut (ASII dengan skor -1,9649, AUTO dengan skor -2,8650, BOLT dengan skor -3,5780, GDYR dengan skor $-1,5123$, BRAM dengan skor -2,7536, PRAS dengan skor -1,1647, dan SMSM dengan skor -3,6070) dan hanya 1 perusahaan otomotif diprediksikan mengalami kebangkrutan (IMAS dengan skor 0,0718).

Pada tahun 2017 semua perusahaan diprediksikan tidak mengalami kebangkrutan. Adapun masing-masing skor setiap perusahaan adalah ASII dengan skor -1,9715, AUTO dengan skor $-2,9281$, BOLT dengan skor -2,4209, GDYR dengan skor -1,1035, BRAM dengan skor $-3,0362$, IMAS dengan skor -0,2986, PRAS dengan skor -1,1522, dan SMSM dengan skor $-3,9023$.

\section{Perbandingan Hasil Prediksi Kebangkrutan Metode Altman (Z- Score), Metode Springate (S-score) dan Metode Zmijewski}

Setelah mengetahui nilai dari setiap masing-masing metode yang digunakan dalam memprediksi kebangkrutan, maka selanjutnya adalah membandingkan persentase tingkat kebangkrutan tiap perusahaan dari tiap-tiap metode. Hasil perhitungan perbandingan ketiga metode adalah sebagai berikut :

Tabel 1. Persentase Perbandingan Tiga Metode

\begin{tabular}{|c|c|c|c|}
\hline \multirow{2}{*}{ Kategori } & \multicolumn{3}{|c|}{ Presentase Perbandingan 3 Metode } \\
\cline { 2 - 4 } & Altman (Z score) & Springate (S-score) & Zmijewski \\
\hline Bangkrut & $25,00 \%$ & $66,67 \%$ & $8,33 \%$ \\
\hline Tidak Bangkrut & $8,33 \%$ & $33,33 \%$ & $91,67 \%$ \\
\hline Grey Area & $66,67 \%$ & & \\
\hline
\end{tabular}

Sumber : Data Olahan Penulis, 2018

\section{KESIMPULAN DAN SARAN \\ Kesimpulan}

Berdasarkan hasil analisa dan pembahasan sebelumnya, perusahaan-perusahaan yang menjadi obyek penelitian mempunyai tingkat kesehatan yang berbeda-beda. Berikut kesimpulan dari penelitian yang sudah dibahas : 
- Dari perhitungan metode Altman Z- score, diketahui bahwa persentase untuk keseluruhan perusahaan yang mengalami kategori kebangkrutan sebesar 25,00\%, kategori perusahaan sehat (tidak bangkrut) sebesar 8,33\%, dan kategori perusahaan grey area sebesar 66,67\%. Dari perhitungan ini, diketahui bahwa PT Selamat Sempurna Tbk adalah perusahaan yang termasuk kategori sehat dan setiap tahunnya menunjukan peningkatan yang cukup baik dibandingkan dengan perusahaan otomotif lainnya.

- Metode kebangkrutan Springate (S-score), diketahui bahwa dengan menggunakan metode ini, tingkat kebangkrutan yang dialami perusahaan-perusahaan persentasenya lebih banyak sebesar $66,67 \%$ prediksi akan bangkrutnya perusahaan muncul dari semua obyek penelitian dan sebesar 33,33\% perusahaan dikatakan sehat (tidak bangkrut).

- Metode ketiga yang digunakan adalah metode Zmijewski. Dari hasil perhitungan, tingkat kebangkrutan yang dialami lebih sedikit dan perusahaan yang termasuk ke dalam kategori sehat lebih banyak yakni sebesar $91,67 \%$ dan sisanya sebesar $8,33 \%$ dinyatakan bangkrut.

- $\quad$ Perbandingan dari ketiga metode yaitu Altman (Z- score), Springate (S- score), dan Zmijewski, diketahui bahwa tingkat kebangkrutan yang tinggi yang dialami oleh perusahaan yang dihitung menggunakan metode Springate $(S$-score). Persentase kebangkrutan yang ditunjukkan pada metode Springate ini lebih tinggi daripada metode- metode lain, yakni sebesar 66,67\%. Sebaliknya, dalam metode Zmijewski menunjukkan bahwa perusahaan yang berada dalam ketegori sehat (tidak bangkrut) persentasenya lebih tinggi dari metode-metode lain, yaitu sebesar 91,67\%.

\section{Saran}

Berdasarkan hasil penelitian yang telah dilakukan, maka peneliti ingin memberikan beberapa saran sebagai berikut :

- Bagi perusahaan yang berada dalam kondisi sehat, hendaknya terus memperhatikan, mempertahankan dan meningkatkan kinerja keuangannya sehingga perusahaan dapat terhindar dari kemungkinan kebangkrutan. Sedangkan bagi perusahaan yang terindikasi memiliki potensi untuk mengalami kebangkrutan, maka diharapkan agar pihak manajemen perusahaan dapat segera mengambil tindakan untuk dapat memulihkan kondisi keuangan perusahaan, misalnya dengan cara mengurangi liabilitas dan meningkatkan profit perusahaan dengan melakukan efisiensi biaya -biaya perusahaan.

- Investor dalam melakukan keputusan investasi harus lebih selektif dan berhati-hati memilih perusahaan dan disarankan untuk memilih perusahaan yang menunjukkan peningkatan kinerja keuangan atau menunjukan kinerja keuangan yang baik sehingga lebih aman. Sebaiknya dapat menggunakan hasil penelitian sebagai salah satu rujukan dalam membuat keputusan investasi serta dalam memilih perusahaan .

- Bagi peneliti selanjutnya sebaiknya dapat menambah jumlah periode pengamatan dan dapat menambah model analisis lain seperti model Olhson, Grover, Fullmer H-score dan lainnya sebagai model tambahan dalam melakukan perbandingan untuk mengetahui sehat tidaknya suatu perusahaan serta menganilisis kondisi keuangan suatu perusahan.

\section{DAFTAR PUSTAKA}

Haruna, Danjuma \& Worsen. (2016). The Effect of Public Perceptionson Financial Statements of Nigerian Banks: An Expository Survey of Taraba State. The International Journal of Business \& Management (ISSN 2321- 8916). January 2016.

Lili \& Trisnadi. (2013). Analisis Komparatif dalam Memprediksi Kebangkrutan pada PT. Indofood Sukses Makmur Tbk. Jurusan Manajemen Keuangan, STIE MDP, Palembang. 
Safitri, Aprilia \& Hartono, Ulil. (2014). Uji Penerapan Model Prediksi Financial distress Altman, Springate, Ohlson dan Zmijewski pada Perusahaan Sektor Keuangan di Bursa Efek Indonesia. Jurnal Ilmu Manajemen Volume 2 no 2 April 2014, PP: (328-337).

Sugiyono. (2008). Metode Penelitian Administrasi dilengkapi dengan Metode $R \& D$. Cetakan ke- 19. Bandung: Penerbit Alfabeta Bandung

http://www.idx.co.id (Di akses pada tanggal 5 Agustus 2017, pukul 20.15 WIB)

https://biz.kompas.com/read/2017/08/31/122538328/menilik-kontribusi-industri-otomotifbagi-tanah-air-dari-masa-ke-masa (Di akses pada tanggal 29 September 2017, pukul 20.15 WIB)

http://www.kemenperin.go.id/artikel/18487/Produsen-Otomotif-Nasional-Terapkan-SistemIndustry-4.0 (Di akses pada tanggal 29 September 2017, pukul 21.20 WIB)

http://ioaddakhil.blogspot.co.id/2014/02/pengertian-teori-sinyal.html (Di akses pada tanggal 20 Juli 2018, pukul 20.20 WIB) 
